\title{
A review of research methods for evaluation and analysis of suitability of well-facilitated farmland construction
}

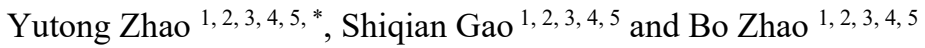 \\ ${ }^{1}$ Institute of Land Engineering and Technology, Shaanxi Provincial Land Engineering Construction Group Co., Ltd. 710075, Xi'an, \\ China \\ ${ }^{2}$ Shaanxi Provincial Land Engineering Construction Group Co., Ltd. 710075, Xi'an, China \\ ${ }^{3}$ Key Laboratory of Degraded and Unused Land Consolidation Engineering, the Ministry of Natural Resources, 710075, Xi'an, China \\ ${ }^{4}$ Shaanxi Provincial Land Consolidation Engineering Technology Research Center.710075, Xi' an, China \\ ${ }^{5}$ Land Engineering Quality Testing of Shaanxi Land Engineering Construction Group Co., Ltd. Shaanxi, China
}

\begin{abstract}
The setting direction of the evaluation indicators in the current research and the differences of the research methods in terms of principles, advantages and disadvantages and applicability are compared and analyzed. The results show that the current well-facilitated farmland construction has achieved remarkable results. In the suitability evaluation research before project construction, the setting of evaluation indicators focuses more on the natural endowment conditions of regional cultivated land; in the benefit evaluation research after project construction, from The early focus on economic benefit evaluation has gradually developed into an equal emphasis on economic, social and ecological benefit evaluation; in the analysis of influencing factors, the current research is still relatively weak, and there are still few explanations for the differences in the level of benefit improvement in different construction areas. Regarding research methods, future research should comprehensively consider the advantages, disadvantages and applicability of different methods. This study can provide a useful reference for scientifically promoting well-facilitated farmland construction.
\end{abstract}

Key words: Well-facilitated farmland; Method comparison.

\section{Introduction}

The arable land resources of China are extremely precious, The per capita arable land area is only $0.08 \mathrm{hm} 2$, which is far below the global average[1-2]. Before 20th century, cultivated land resources have not been well protected. Since the reform and opening up, with the rapid social and economic development, the central government has gradually realized the serious food security problems caused by the reduction of cultivated land, and formulated and promulgated various policies to protect cultivated land. Since 1997, China has begun to vigorously summarize and promote the experience of land consolidation to improve the quality of cultivated land. In 2010, the Fifth Plenary Session of the Seventeenth Central Committee of the Communist Party of China proposed "large-scale construction of well-facilitated farmland for drought and flood protection".

Well-facilitated farmland refers to the land that is leveled, concentrated and contiguous, with complete facilities, agricultural power supply, fertile soil, good ecology, strong disaster resistance, and is compatible with modern agricultural production and management methods. It is designed as permanent basic farmland. Of arable land.
Maintaining a certain amount of Well-facilitated farmland is of great significance for realizing the "equal emphasis on the quality" of farmland protection and meeting the rigid growth needs of major agricultural products such as grain. The construction of Well-facilitated farmland is an important part of China's land consolidation plan. Compared with traditional land reclamation, Wellfacilitated farmland has been further improved and expanded in terms of construction content and construction requirements. It is an important strategic measure to increase the comprehensive production capacity of cultivated land, improve the agricultural production environment, ensure food security, and develop modern agriculture. . Well-facilitated farmland construction projects involve pre-evaluation of regional survey and planning site selection, follow-up and monitoring during the construction process, postevaluation of comprehensive benefit evaluation and management, etc. Each stage is to ensure the long-term benefits of the project and guarantee the finances. An important link in the safe and efficient application of funds. Therefore, carry out the regional suitability evaluation before the construction of Well-facilitated farmland, the benefit evaluation research after the project

\footnotetext{
* Corresponding author: 285725361@qq.com
} 
construction, and the analysis of the factors that affect the benefit of the project after the construction. Timely adjustment of management measures and other aspects have important theoretical and practical significance. Since 2010, the central government clearly proposed the large-scale construction of well-facilitated farmland for droughts and floods, and the related research on the construction of well-facilitated farmland has yielded fruitful results. At present, there is still a lack of literature review on the suitability evaluation research before the construction of well-facilitated farmland projects, the benefit evaluation research after the construction, and the research progress of influencing factors. The research results produced by the setting direction of different evaluation indicators and the selection of research methods are often different. In view of this, in order to make up for the current research gaps, this research focuses on four parts: the background and current situation of well-facilitated farmland construction, the suitability evaluation study before construction, the benefit evaluation after construction, and the study of factors affecting the benefit of construction projects. It sorts out the selection of research methods and summarizes and summarizes the principles, advantages and disadvantages and scope of application of different research methods adopted by current scholars, aiming to provide a useful reference for scientifically and rationally promoting well-facilitated farmland construction work and research.

\section{The current situation of Well- facilitated farmland construction}

Land consolidation and well-facilitated farmland construction have promoted the protection of arable land resources and the improvement of comprehensive grain production capacity in China, with remarkable results. From 2001 to 2005 , China has invested nearly 100 billion yuan in land consolidation funds and added 1.4267 million hectares of cultivated land, achieving a balance between land occupation and compensation. From 2006 to 2010 , there were more than 150,000 land remediation projects in China's audit collection database, with a remediation scale of 8.29 million hectares and an increase of 2.7 million hectares of cultivated land. According to remote sensing monitoring, by 2010, China's high, medium, and low-yield fields accounted for $20.66 \%$, $39.56 \%$, and $39.78 \%$ of the country's arable land, respectively. According to the National Land Rehabilitation Plan, from 2011 to 2015 , 530 million mu of agricultural land will be reorganized nationwide, and 26.7 million ha of well-facilitated farmland will be built.
Table 1. Index selection for suitability evaluation

\begin{tabular}{|c|c|c|}
\hline Target & Criterion & index \\
\hline \multirow{3}{*}{$\begin{array}{c}\text { Regional } \\
\text { natural } \\
\text { endowments }\end{array}$} & Site conditions & Altitude, slope \\
\hline & Soil quality & $\begin{array}{c}\text { Soil surface } \\
\text { thickness }\end{array}$ \\
\hline & Space Form & $\begin{array}{c}\text { Field } \\
\text { concentration }\end{array}$ \\
\hline \multirow{2}{*}{$\begin{array}{c}\text { Infrastructure } \\
\text { and } \\
\text { Construction } \\
\text { Conditions }\end{array}$} & $\begin{array}{c}\text { location } \\
\text { accessibility }\end{array}$ & $\begin{array}{c}\text { Field road } \\
\text { accessibility }\end{array}$ \\
\hline & $\begin{array}{l}\text { Irrigation and } \\
\text { drainage } \\
\text { conditions }\end{array}$ & $\begin{array}{c}\text { Irrigation } \\
\text { water quality }\end{array}$ \\
\hline \multirow{2}{*}{$\begin{array}{l}\text { development } \\
\text { stability }\end{array}$} & $\begin{array}{l}\text { Socioeconomic } \\
\text { conditions }\end{array}$ & $\begin{array}{c}\text { Per capita } \\
\text { agricultural } \\
\text { output }\end{array}$ \\
\hline & Acceptability & $\begin{array}{c}\text { Public } \\
\text { satisfaction }\end{array}$ \\
\hline
\end{tabular}

Through land consolidation and reclamation, a large amount of fragmented and scattered land has been appropriately merged, and the supporting construction of agricultural infrastructure has been clearly strengthened. After the improvement, the quality of cultivated land has increased by one grade on average, the yield per unit has increased by $10 \%$ to $20 \%$ on average, and the new grain production capacity will be 37.368 billion $\mathrm{kg}$, which has improved the comprehensive production capacity of cultivated land. At present, the construction of wellfacilitated farmland has achieved results nationwide, but there are still many problems. For example, in terms of the rationality of project layout, there is a lack of differentiated planning and layout; in terms of fund deployment and management and protection, departmental project construction funds are scattered, it is difficult to form a joint force to play the expected role, and the long-term management and protection mechanism after the construction project is still incomplete Wait. Faced with the new situation and new requirements, the National Land Rehabilitation Plan proposes that during the 13th Five-Year Plan period, it is necessary to ensure that the country will build 206.7 million $\mathrm{hm} 2$, and strive to achieve 40 million $\mathrm{hm} 2$ well-facilitated farmland, of which 1553 million to 200.7 million $\mathrm{hm} 2$ will be built through land improvement. The quality of the renovated basic farmland has increased by 1 grade on average.

\section{Suitability evaluation of well- facilitated farmland before construction}

The rational layout and scientific planning of wellfacilitated farmland construction sites need to comprehensively consider the natural attributes of regional farmland and the suitability of social and economic construction [3]. The quality evaluation of regional arable land is not only a measure of arable land productivity, but also closely related to the natural quality, construction potential, agricultural infrastructure conditions, project capital investment and construction direction of the arable land itself. Scientifically delimiting well-facilitated farmland construction areas, and 
clarifying the degree of difficulty, construction potential, and construction direction of different types of areas are crucial for the orderly development of well-facilitated farmland construction. Therefore, the construction suitability evaluation research of regional cultivated land is often used as an important basis and basis for the delineation of key construction areas and construction timing.

The study found that in the setting of the target layer, the existing research mainly focuses on the regional natural endowment conditions, infrastructure and construction conditions, and the development stability after project construction. Some scholars further focus on policy planning [4], ecological security, etc. have been extended from other angles. In the setting of the criterion layer and the index layer, the natural endowment of the regional cultivated land is mostly concerned. The selection of indicators is mainly based on site conditions, natural quality of soil, spatial form of cultivated land, etc. [5]; in terms of infrastructure and construction conditions, emphasis is placed on location accessibility and the importance of farmland irrigation and drainage conditions; In terms of development stability after construction, it is mainly considered from the ex setting of the current construction suitability evaluation research involves the natural conditions, social and economic conditions of the construction area, etc. The proportion of the index selection based on the natural endowment condition of the regional cultivated land is relatively large, while the selection of the index considering the local human factors is relatively large. less. At the same time, the setting and evaluation of the index system

There are cross-cutting issues in content.

\section{Research on the factors affecting the benefits after the construction of well-facilitated farmland}

Well-facilitated farmland construction is a comprehensive adjustment and transformation of regional land use structure, layout and function. China has a vast territory, uneven distribution of resources, and large regional differences in agricultural resource conditions and social and economic development. According to existing research, the influencing factors of the benefits of wellfacilitated farmland construction projects can be summarized into three aspects: natural factors, social and economic factors, and human factors in the construction area. In terms of natural factors, some researchers have discussed the influence of the topography, landform, slope, soil quality, climatic conditions, frequency of natural disasters, and water resources development and utilization conditions on the benefits of the construction area. In the existing layout, some areas have superior agricultural resources and good basic conditions for wellfacilitated farmland construction. At the same time, there are also a certain number of well-facilitated farmland project areas where the construction area is low in arable land productivity, water resources shortage, groundwater over-exploitation and other constraints, which will have a certain impact on the benefits of the project after the completion of the project. In terms of socio-economic factors, some scholars have qualitatively analyzed the possible impacts of regional GDP, urbanization rate, labor conditions, and agricultural output. In terms of human factors, the artificial management and protection of agricultural infrastructure in the later stage, the construction and protection of road and forest network, and the application and promotion of water-saving irrigation technology have a certain impact on the benefits of well-facilitated farmland construction [6].

In the research on the influencing factors of the postconstruction benefits of well-facilitated farmland projects, the relevant research methods mainly include factor analysis, multiple regression analysis, principal component analysis, path analysis, grey correlation analysis, and Logistic regression analysis. Among the multivariate statistical methods, principal component analysis (PCA) and factor analysis (FA) are widely used and are commonly used multivariate analysis methods. This kind of method can reduce the dimensionality of the proposed many influencing factors, synthesize the indicators in the evaluation system into several common factors with a small number, and retain as much original variable information as possible and are not related to each other, so as to achieve The purpose of reproducing the internal relationship between the original variables and factors is suitable for the study of the factors affecting the benefits after the construction of well-facilitated farmland.

However, the inability to ensure the full utilization of data is the main disadvantage of this type of analysis method. For this reason, some scholars use this type of analysis method as the basis for judging the validity of multiple regression, which can avoid the defect of discarding a large number of data while ensuring that the main explanatory common factors can be retained in the regression equation. Combined with the ridge regression analysis, it can effectively solve the multilinear problem of the data under the premise of ensuring the full use of the data. The advantage of gray correlation analysis (GCA) is that it can determine the degree of influence between systematic factors according to the degree of similarity or dissimilarity in the development trend between factors, that is, the "gray correlation degree", which affects the number of samples or samples. The same applies with or without rules. This method has a relatively small amount of calculation, and can sort the relative benefit levels of well-facilitated farmland construction projects in a certain area, and can explore the relevant indicators that affect the benefits. If you want to further explore the influence relationship between independent variables and dependent variables, the advantage of path analysis (PA) is that it can intuitively describe the direct and indirect influence between the respective variables and between the independent variable and the dependent variable degree. The method can decompose the correlation coefficient on the basis of multiple regression, and express the direct effect of an independent variable on the dependent variable, the indirect effect of other variables on the dependent variable, and the direct path, indirect path and total path coefficient respectively. combined effect. Logistic regression analysis is a widely used 
statistical model, which is a kind of generalized linear model. The generalized linear model is a generalization of the linear regression model, which can overcome the shortcomings of the linear regression model. In the field of geosciences, a large number of scholars use this model to predict and simulate and analyze the driving force of land use change. The independent variable input to the logistic regression model can be discrete or continuous, or it can be a categorical variable with multiple values. The contribution of the independent variable to the dependent variable is generally quantitatively explained by the odds ratio (OR) or marginal effect. This method is suitable for well-facilitated farmland benefit-influencing factors research and benefit-level prediction research, but the use of such methods can only clarify the dependence between dependent variables and independent variables, and the interpretation of causal relationships requires further use of relevant theories.

To sum up, among the multivariate statistical methods, regression analysis, principal component analysis, factor analysis and other methods are widely used, but at the same time there is collinearity, the quantitative relationship between independent variables and dependent variables cannot be clearly defined, and the lack of Further interpretation of the dependent variable and other issues. The advantage of the path analysis method is that it can use the path diagram to succinctly elucidate the relationship between the variables. Influence relationship between standard farmland benefits and influencing factors. The advantage of logistic regression analysis is that it is easy to deal with various types of data, can explain the occurrence probability of dependent variables, and helps researchers deal with influencing factors that are difficult to quantify. Prediction research has certain significance for the optimal layout of wellfacilitated farmland.

\section{Conclusion}

In the research part of factors affecting the improvement of well-facilitated farmland benefits, both in terms of index selection and method research are still relatively weak, and there are still few explanations for the differences in benefit evaluation and benefit improvement levels after the construction of well-facilitated farmland projects. Principal component analysis, factor analysis and other methods can retain as much original variable information as possible, and cannot guarantee full utilization of data is the disadvantage of such methods. Combined with regression analysis, it can effectively solve the multi-linear problem of the data while ensuring the full use of the data; the path analysis method can intuitively describe the degree of direct and indirect influence between the respective variables and between the independent variable and the dependent variable ; Logistic regression analysis is suitable for well-facilitated farmland benefit factor research and benefit level prediction research, and researchers still need to rely on relevant theories to explain the causal relationship.

\section{Acknowledgments}

This work was financially supported by Innovation Capability Support Program of Shaanxi (Program No.2021PT-053) fund.

\section{References}

1. Qiang W L, Liu A, M, Cheng S K, et al. Agricultural trade and virtual land use: The case of China's crop trade[J].Land Use Policy, 2013,33(33):141-150.

2. Du X D, Zhang $X K$, Jin $X$ B. Assessing the effectiveness of land consolidation for improving agricultural productivity in China[J]. Land Use Policy,2018,70:360-367.

3. Tian J S, Tian J J, Guo J C. Evaluation of comprehensive benefits of land consolidation based on AHP and Fuzzy[J].Asian Agricultural Research, 2013,1(1):17-20.

4. Abubakari Z, van der Molen P, Bennett R M, et al. Land consolidation, customary lands, and Ghana's Northern Savannah Ecological Zone: An evaluation of the possibilities and pitfalls[J]. Land Use Policy,2016,54:386-398.

5. Wang J, Lin Y F, Glendinning A, et al. Land-use changes and land policies evolution in China's urbanization processes[J].Land Use Policy,2018,75:375-387.

6. Minetos D, Polyzos S. Deforestation processes in Greece: A spatial analysis by using an ordinal regression model[J].Forest Policy \& Economics,2010,12(6):457-472. 